Working Paper No. 598, 2003

The Firm as a Pool of Factor Complementarities

by Assar Lindbeck and Dennis J. Snower

IUI, The Research Institute of Industrial Economics

P.O. Box 5501

SE-114 85 Stockholm

Sweden 


\title{
The Firm as a Pool of Factor Complementarities
}

\author{
Assar Lindbeck and Dennis J. Snower
}

10 June 2003

\begin{abstract}
This paper presents a new approach to the theory of the firm by identifying factor complementarities as central to the determination of the firm's boundaries. The factor complementarities may take a variety of forms: technological and informational complementarities, as well as economies of scale and scope. We examine the tradeoff between the gains from these complementarities and transactions costs. In so doing, we must abandon the standard dichotomy between the determinants of plant size and firm size. The influence of factor complementarities on firm size is examined in partial and general equilibrium frameworks.
\end{abstract}


The modern literature on the boundaries of the firm focuses primarily on three major costs of organizing firms: communication and coordination costs (e.g. Coase (1937) and Williamson (1975)); principal agent problems (e.g. Alchian and Demsetz (1972), Holmstrom (1982)); and hold-up problems (e.g. Klein, Crawford and Alchian (1978), Grout (1984)). Broadly speaking, these costs may be viewed as different types of transactions costs. They have also given rise to the notion that the firm may be identified as a system of property rights (e.g. Grossman and Hart (1986)), an incentive system (e.g. Holmstrom and Milgrom (1994)), and a communication network (e.g. Bolton and Dewatripont (1994)), and so on.

Another literature deals with plant size (e.g. Viner (1932), Robinson (1958), Baumol, Panzer and Willig (1982)). This literature emphasizes technological considerations, such as fixed costs and economies of scale and scope. In the literature on the size of firms, it is generally taken for granted that the factors affecting plant size (in particular, economies of scale and scope) are not relevant to firm size. Our paper calls this conventional wisdom into question.

Our analysis instead identifies the firm as a "pool of factor complementarities," and we examine how these complementarities interact with transactions costs. ${ }^{1}$ When these interactions are taken into account, we must abandon the dichotomy between the determinants of plant size and of firm size. Both sets of influences have a role to play in the determination of the firm's boundaries. But since the role of factor complementarities has not received much attention in the recent literature on the firm's boundaries, we will focus on this aspect here, while transactions costs will be modeled quite schematically.

The paper is organized as follows. Section 1 deals with preliminaries, outlining various types of factor complementarities and their implications for the boundaries of the firm. Section 2 runs through some simple, partial equilibrium models to show how these complementarities influence the firm's boundaries. Section 3 presents a general equilibrium model in which the boundaries of different firms affect one another and are determined simultaneously, so as to yield a model of market structure (viz., the degree of imperfect competition). Section 4 concludes.

\section{Preliminaries}

Factor complementarities (and substitutabilities) come in various guises. First, the technological complementarities (and substitutabilities) may be identified in terms of the cross-partial derivatives in

\footnotetext{
${ }^{1}$ Our work extends the analysis of Lindbeck and Snower (1996, 2000). Whereas the latter focuses on intra-personal complementarities, we are concerned with inter-factor (particularly inter-personal) complementarities.
} 
a production function. For the production function $Q=f(\mathbf{F})$, where $\mathbf{F}=\left(F_{1}, \ldots, F_{n}\right)$ is a vector of factors, the factors $F_{i}$ and $F_{j}$ are technological complements when $\frac{\partial^{2} Q}{\partial F_{i} \partial F_{j}}>0$ and technological substitutes when $\frac{\partial^{2} Q}{\partial F_{i} \partial F_{j}}<0$.

Second, there are informational complementarities among different types of labor. Specifically, suppose that through learning-by-doing, each type of worker gains information that is useful to other types of workers. In practice, the natural domain for such informational complementarities is the firm (rather than its plants), because firms generally encourage the exchange of knowledge among their employees, but often strongly discourage them from sharing it with employees in other firms ${ }^{2}$ Thus the natural domain of informational complementarities is the firm, rather than its plants. Let $H$ be the firm's knowledge capital, which is a public good within the firm but not beyond it. Let $H=H(\mathbf{L})$ be the firm's production function for knowledge capital, ${ }^{3}$ where $\mathbf{L}=\left(L_{1}, \ldots, L_{m}\right)$ is a vector of labor types. The firm's production function (different from the one above) may be expressed as $Q=f\left[g_{1}(H) L_{1}, \ldots, g_{m}(H) L_{m}\right]$, where $g_{i}(H)$ describes how the firm's knowledge capital enhances the productivity of type- $i$ labor, so that $g_{i}(H) L_{i}$ is type-i labor in efficiency units. Then, in the absence of technological complementarities $\left(f_{L_{1} L_{2}}=0\right)$, the informational complementarties between labor of types $i$ and $j(i \neq j)$ are $^{4} \frac{\partial^{2} Q}{\partial L_{i} \partial L_{j}}=\left(H_{L_{i} L_{j}}+H_{L_{i}} H_{L_{j}}\right)\left(f_{L_{i}} g_{i}^{\prime}+f_{L_{j}} g_{j}^{\prime}\right)>0$.

Third, in contrast to the inter-factor complementarities above, there are intra-factor complementarities (or substitutabilities). Specifically, consider a vector of factors $\mathbf{F}=\left(F_{1}, \ldots, F_{I}\right)$ producing the output $Q=f(\mathbf{F})$, and now consider a proportional increase in all the factors $\Delta \mathbf{F}=\mu \mathbf{F}$ producing the additional output $\Delta Q$, where $\mu(>1)$ is a constant. If the two sets of factors, $\mathbf{F}$ and $\Delta \mathbf{F}$, are complementary, then $\Delta Q>\mu Q$ (increasing returns to scale). If the two sets are substitutable, then $\Delta Q<\mu Q$ (diminishing returns to scale); and if the two sets are independent, then $\Delta Q=\mu Q$ (constant returns to scale). In this way, returns to scale may be identified as the outcome of intra-factor complementarities or substitutabilities.

Fourth, there are complementarities (or substitutabilities) among the same set of factors in the production of additional products. In particular, suppose that the vector of factors $\mathbf{F}$ is used to produce a vector of goods $\mathbf{Q}=\left(Q_{1}, \ldots, Q_{n}\right)$ via the production function $\Phi(\mathbf{Q})=\Psi(\mathbf{F})$. Let the cost function $C(\mathbf{Q})$ be the solution to the problem of minimizing the factor cost $\mathbf{p F}$ (where $\mathbf{p}$ is a vector of factor

\footnotetext{
${ }^{2}$ They often even have various sanctions - legal and economic - to prevent sensitive information about the firm from reaching their competitors.

${ }^{3}$ Under learning by doing, knowledge is created as an automatic by-product of working in the firm. The production function for knowledge capital shows how the stock of knowledge available to the firm depends on the labor services of all labor types.

${ }^{4}$ Observe that these complementarities operate solely through the exchange of knowledge, and thus are distinct from the technological complementarities that operate through the cross-partials of the production function.
} 
prices) subject to the above production function (for given $\mathbf{Q}$ ). Similarly, let $C_{i}\left(Q_{i}\right)$ be the minimum factor cost of producing just output $Q_{i}$ (an element of the output vector $\mathbf{Q}$ ). If the use of factors in the production of goods $Q_{i}$ and $Q_{j}(j \neq i)$ is complementary, then there are increasing returns to scope, so that $C(\mathbf{Q})<\sum_{i=1}^{n} C_{i}\left(Q_{i}\right)$, where $n$ is the number of goods under consideration. Alternatively, if $C(\mathbf{Q})>\sum_{i=1}^{M} C_{i}\left(Q_{i}\right)$, then there are diminishing returns to scope; and if $C(\mathbf{Q})=\sum_{i=1}^{M} C_{i}\left(Q_{i}\right)$, there are constant returns to scope. In this way, returns to scope may be viewed in terms of factor complementarities or substitutabilities in the production of different goods. ${ }^{5}$

We will show how the factor complementarities above interact with transactions costs in setting the boundaries of the firm. We define the firm's boundaries as an array $\left(Q_{1}, \ldots, Q_{n}\right)$, specifying the amounts of all outputs that the firm produces. The number of elements in this vector describes the firm's scope and the magnitude of all the elements describes its size. To highlight how the various factor complementarities above can affect the boundaries of the firm (rather than merely influencing plant size), we will focus on complementarities and transactions costs that are firm-wide (rather than merely plant-wide) ${ }^{6}$

It is commonly alleged that although technological phenomena - such as inter-factor complementarities, economies of scale and scope - are relevant to plant size, they are irrelevant to firm size, for two reasons. First, technological economies allegedly set no lower limit to firm size, since the underlying factors may be controled by more than one firm. Second, technological diseconomies allegedly set no upper limit to firm size, since the firm is always at liberty to split into independent subsidiaries and thus avoid such diseconomies. ${ }^{7}$

One reason for calling this conventional wisdom into question is that it is generally inefficient for more than one firm to control a common set of complementary factors. If there were multiple domains of authority to decide how such factors are to be used, the different firms would need to be engaged in an ongoing process of bargaining. Conducting these bargains would be costly and possibly vulnerable to hold-up, without countervailing benefits. For this reason, it is efficient for a single firm to have exclusive right over a given set of factors.

Moreover, firms generally cannot avoid diseconomies through the creation of subsidiaries as an alternative to market transactions among independent firms, because there is an important difference

\footnotetext{
${ }^{5}$ Returns to scope may of course also arise if factor prices change with factor use in such as way as to drive a wedge between $C(\mathbf{Q})$ and $\sum_{i=1}^{M} C_{i}\left(Q_{i}\right)$.

${ }^{6}$ For example, technological complementarities between different factors may span several plants, as when several plants make use of a common firm facility, e.g. a storage facility, advertising, or recruitment. For analogous reasons, economies of scale and scope may cover several plants as well. Informational complementarities may also extend across plants, such as when workers in different plants share a common data base or participate in common teams. The transactions costs in our analysis will also be firm-wide.
}

${ }^{7}$ See, for example, Tirole (1989, p. 20-21). 
between a subsidiary and an independent firm. If the subsidiary goes bankrupt, the parent company is financially liable; whereas bankruptcy of another firm has no direct financial implications for the company in question. Thus it is legally impossible for a firm to split itself up into totally independent units. It follows that the managers of a firm have a natural responsibility, and hence interest, in the running of their subsidiaries. For these reasons, managers are unable to avoid intervening in the activities of subsidiaries, and thus firms cannot escape the standard diseconomies of scale and scope such as those caused by bureaucratic waste, internal politiking, the scarcity of entrepreneurial talent and the associated cost of giving entrepreneurs additional responsibilities, and so on ${ }^{8}$ - by having subsidiaries with complete autonomy.

With this in mind, we now proceed to show how factor complementarities, in conjunction with transactions costs, affect the boundaries of the firm.

\section{Factor Complementarities and the Boundaries of a Firm}

This section presents a partial-equilibrium analysis of the firm, examining the firm in isolation from other firms. (General equilibrium is covered in the next section.) We consider the different types of factor complementarities in turn.

\subsection{Economies of Scale}

In the presence of economies of scale for firms (such as economies of marketing and product design, or those related to customer good will for a firm), there is a tradeoff: while increasing the size of the firm enables it to exploit these economies, it also generates additional transactions costs. To focus on firm-wide economies, we consider a firm that produces a homogeneous good $(Q)$ through $x$ identical plants, each of which may be viewed as a bundle of factors $(\mathbf{F}) .{ }^{9}$ The firm 's economies of scale across plants be represented by the following production function

$$
q=A x^{1+\alpha}
$$

where $A$ and $\alpha$ are positive constants, measuring the magnitude of the scale economies.

Let each plant have a fixed operating cost of $\kappa$ per period of analysis. The firm's transactions costs

\footnotetext{
${ }^{8}$ Further limits to the boundaries of the firm are given by sources of firms' finance. To achieve portfolio diversification, lenders commonly prefer lending to a number of independent firms rather than to a single firm with an equivalent number of subsidiaries.

${ }^{9}$ Then the size of the firm can be measured by the number of its plants.
} 
are specified in a simple, stylized way, to capture the usual picture of transactions costs increasing with the size of the firm. ${ }^{10}$ In particular, we assume that the firm's transactions costs (viz., the sum of the internal and external transactions costs) are given by

$$
z=B x^{1+\beta}
$$

where $B$ and $\beta$ are positive constants, so that the transactions costs rise at an increasing rate with the number of plants. This general representation is convenient and appropriate for our purposes because our analysis is concerned only with transactions costs insofar as they are affected by the number of plants (or scale of factor use). We may interpret our transactions cost function as showing how a rise in the number of plants increases search costs for factor inputs and customers, communication costs among employees, or the cost of hold-up and principal-agent problems within the firm.

In this context, we can analyze the degree of horizontal integration. The firm maximizes its profit $\pi=A x^{1+\alpha}-\kappa x-B x^{1+\beta}$ with respect to the number of plants $x$. The first-order condition for the optimal number of plants (or scale of factor use) is

$$
\frac{\partial \pi}{\partial x}=A(1+\alpha) x^{\alpha}-\kappa-B(1+\beta) x^{\beta}=0
$$

This condition implies that the magnitude of the scale economies has a positive effect on the size of the firm: ${ }^{11}$

$$
\frac{\partial x}{\partial A}, \frac{\partial x}{\partial \alpha}>0
$$

It is straightforward to extend this analysis to cover a firm's degree of vertical integration. Specifically, suppose that the final output is produced by means of a chain of intermediate goods. For

\footnotetext{
${ }^{10}$ These are the sum of the internal transactions costs (arising within the firm) and external transactions costs (arising from the firm's market transactions with other firms). Although in practice this sum is not always monotonically increasing in the size of the firm, the firm in our model has an incentive to expand until it reaches the range in which further increases in firm size to lead to increases in the sum of the transactions costs.

${ }^{11}$ By the implicit function theorem, $\frac{\partial\left(\frac{\partial \pi}{\partial x}\right)}{\partial A}=-\frac{\partial \frac{\partial \pi}{\partial x} / \partial A}{\partial \frac{\partial \pi}{\partial x} / \partial x} ; \partial \frac{\partial \pi}{\partial x} / \partial x<0$ by the second-order condition, and $\partial \frac{\partial \pi}{\partial x} / \partial A>0$.
} 
simplicity, consider the following vertical production chain:

$$
\begin{aligned}
q(1)= & A x^{1+\alpha(0)} \\
q(2)= & q(1)^{1+\alpha(1)} \\
q(3)= & q(2)^{1+\alpha(2)} \\
& \cdots \\
q(S)= & q(S-1)^{1+\alpha(S-1)}
\end{aligned}
$$

In the first stage of production, the intermediate good $q(1)$ is produced by means of the factor bundles $x$ (which were interpreted as plants in the previous model). In the next stage, the intermediate good $q(2)$ is produced by means of the intermediate good $q(1)$; and so on. At each production stage, the economies of scale are given by the parameter $\alpha(i), i=0, \ldots, S$, where $S$ is the number of productive stages integrated (vertically) in the firm. Thus the firm's production function may be expressed as

$$
q(S)=x^{\gamma(S)}
$$

where $\gamma(S)=\prod_{i=1}^{S-1}(1+\alpha(i))$.

Furthermore, let the firm's transactions $\operatorname{costs}^{12}$ be given by

$$
z=B(0) x^{1+\beta(0)}+\sum_{i=2}^{S} B(1) q(i)^{1+\beta(i)}
$$

The firm's profit now is

$$
\begin{aligned}
\pi & =q(S)-\kappa x-z \\
& =x^{\gamma(S)}-\kappa x-B(0) x^{1+\beta(0)}+\sum_{i=2}^{S} B(1) x^{\prod_{j=1}^{i-1}(1+\alpha(j))(1+\beta(i))}
\end{aligned}
$$

to be maximized with respect to $x$. In this context, it is easy to show that a sufficiently large increase in returns to scale $\alpha(j)$ leads to an increase in the profit-maximizing number of production stages $S^{*}$. Thus the firm's degree of vertical integration is affected positively by its economies of scale across production stages.

\footnotetext{
${ }^{12}$ These transactions costs are specified along the same lines as in (2).
} 


\section{$2.2 \quad$ Economies of Scope}

To analyze economies of scope (the degree of horizontal integration), let the potential goods that the firm could produce lie on a unit circle, where the distance between two points on this circle is inversely related to their economies of scope. Moreover, the larger the number of goods the firm produces, the greater are its internal transactions costs. Thus the firm faces a tradeoff between economies of scope and transactions costs. The firm's problem is to find the profit-maximizing length of its product segment on the circle of potential products.

For simplicity, let the revenue from good $i$ be $R\left(Q_{i}\right)$, where $i=1, \ldots, N, R_{Q_{i}}\left(Q_{i}\right)>0$, and $R_{Q_{i} Q_{i}}\left(Q_{i}\right)<0$. Let the production cost be $v N Q_{i}-b \xi(N)$, where $v$ and $b$ are positive constants and $b \xi(N)$ specifies the economies of scope, with $\xi_{N}, \xi_{N N}>0$, so that there are positive economies of scope. The constant $b$ measures the magnitude of these economies of scope. Let the firm's transactions costs associated with the production of each good be $z^{p}\left(Q_{i}\right)$ and its transactions costs associated with the coordination of the production of different goods be $z^{c}(N)$. Note that, for simplicity, the revenues and costs are symmetric across products. Thus the profit-maximizing amounts of different outputs will be equal: $Q_{i}^{*}=Q^{*}$.

Then the firm's profit is $\pi=N R(Q)-v N Q+b \xi(N)-N z^{p}(Q)-z^{c}(N)$. The first-order condition for each output is

$$
R_{Q_{i}}\left(Q_{i}\right)-v-z_{Q_{i}}^{p}\left(Q_{i}\right)=0
$$

which determines the profit-maximizing level of each output. The first-order condition with respect to the number of products is

$$
R\left(Q^{*}\right)-v Q^{*}+b \xi_{N}(N)-z^{p}(Q)-z_{N}^{c}(N)=0
$$

From this condition, it is evident that the greater are the economies of scope $(b)$, the greater the number of goods $(N)$ that the firm produces (i.e. the greater the degree of horizontal integration), and hence the larger the firm:

$$
\frac{\partial N}{\partial b}>0
$$

Note that this result is the outcome of the interaction between economies of scope and transactions costs. In the absence of internal transactions costs, the number of goods per firm and the amount of each good produced would be indeterminate. It is only on account of the internal transactions costs that economies of scope directly affect the boundaries of the firm. 


\subsection{Inter-Factor Complementarities}

Since the role of technological inter-factor complementarities in determining the firm's boundaries may be analyzed along similar lines to the role of economies of scale (above), we focus on informational complementarities here. As employees gain information about their customers, their suppliers, and so on, this new information is added to the firm's stock of knowledge capital. Through this knowledge capital, employees within a firm become complements, even if they do not work within the same plant. The information gained by one employee is communicated and becomes useful in enhancing the productivity of other employees. We present a simple model in which the firm faces a tradeoff between these complementarities and the transactions costs considered above. This model is not meant to be comprehensive or general; it just provides an illustration of how inter-factor complementarities can affect the boundaries of the firm.

Consider a firm that comprises $N$ plants. ${ }^{13}$ Plant $i(i=1, \ldots, N)$ employs $L_{i}$ workers. Workers accumulate knowledge through learning-by-doing; however, unlike the conventional learning-by doing models, the resulting knowledge is useful not just to the employee who acquired it, but to other employees as well. ${ }^{14}$ Let the production of knowledge capital be given by $H=(a L)^{\alpha}$, where $L=$ $\sum_{i=1}^{N} L_{i}$, and $a$ and $\alpha$ are positive constants, $0<\alpha<1$. Moreover, let the output of plant $i$ be $Q=(a L)^{\alpha} L_{i}$. In short, the average productivity of the employees in each plant depends on the knowledge gained by all employees in the firm, which in turn depends on the total employment of the firm. ${ }^{15}$ The constant $a$ measures the degree of informational complementarity among the employees.

Let the transactions costs associated with the employees in plant $i$ be $\frac{1}{1+\eta_{\iota}} L_{i}^{1+\eta_{\iota}}, \eta_{\iota}>0$ (a constant), and let those transactions costs arising from the coordination of the various plants be $\frac{1}{1+\eta_{\chi}} N^{1+\eta_{\chi}}$, $\eta_{\chi}>0$ (a constant). Let wages be determined through bargaining in which workers capture a fraction $\mu$ of the available rent. Then the firm's profit may be expressed as $\pi=(1-\mu) \sum_{i=1}^{N} g(a L) L_{i}-$ $\sum_{i=1}^{N} \frac{1}{1+\eta_{\iota}} L_{i}^{1+\eta_{\iota}}-\frac{1}{1+\eta_{\chi}} N^{1+\eta_{\chi}}$. The first-order conditions are $\left(\partial \pi / \partial L_{i}\right)=0$ and $(\partial \pi / \partial N)=0$, which can be shown to imply:

$$
\begin{aligned}
(1-\mu) a^{\alpha} \frac{1+\alpha}{\alpha} N^{\eta_{\iota}} & =L^{\eta_{\iota}-\alpha} \\
\frac{1-\mu}{\alpha} a^{\alpha} L & =N^{\eta_{\chi}+1}
\end{aligned}
$$

\footnotetext{
${ }^{13}$ It makes no substantive difference whether these plants produce the same product or differentiated products.

${ }^{14}$ The mechanisms are analogous to those covered in some endogenous growth models.

${ }^{15}$ For simplicity, our model is static. For this purpose, we make the implicit assumption that knowledge depreciates 100 percent in moving from one period of analysis to the next. In general, of course, knowledge depreciates more slowly and thus a worker's productivity comes to depend on the stock of knowledge accumulated through all the work done in the firm over the present and past. It is straightforward to extend our model accordingly and generate analogous qualitative results in the steady state.
} 
respectively. Solving these equations simultaneously, we obtain the profit-maximizing number of plants and the profit-maximizing employment level (over all the firm's plants):

$$
\begin{aligned}
N^{*} & =\left(a \frac{1-\mu}{\alpha}\right)^{\frac{\eta_{\iota}-\alpha+1}{\eta_{\chi} \eta_{\iota}+\alpha\left(\eta_{\chi}-1\right)}}(1+\alpha)^{\frac{1}{\eta_{\chi} \eta_{\iota}+\alpha\left(\eta_{\chi}-1\right)}} \\
L^{*} & =\frac{\alpha}{1-\mu} a^{-\alpha \frac{\eta_{\chi}\left(\eta_{\iota}+\alpha\right)-\left(1-\eta_{\iota}\right)}{\eta_{\chi} \eta_{\iota}+\alpha\left(\eta_{\chi}-1\right)}}
\end{aligned}
$$

Since $\eta_{\iota}-\alpha+1>0, \eta_{\chi}-1$, and $\eta_{\chi}\left(\eta_{\iota}+\alpha\right)-\left(1-\eta_{\iota}\right)>0$, we find that an increase in the complementarity among workers (a rise in $a$ ) leads the firm to increase the number of plants and employees per plant:

$$
\frac{\partial N}{d a}>0, \frac{\partial L}{d a}>0
$$

\section{General Equilibrium}

Thus far we have considered the boundaries of an individual firm independently from the boundaries of other firms. We now extend our analysis by putting the behavior of firms into a general equilibrium context, enabling us to investigate the determination of market structure. In a simple analytical framework, we derive simultaneously the number of firms and the size of each firm, and show that these two variables are naturally interdependent.

Our analysis points to a broad vision of firms as institutions designed to exploit factor complementarities. We will show that the greater are these complementarities, relative to the firms' internal transactions costs, the greater will be the size of firms in the general equilibrium and the smaller will be the equilibrium number of firms. ${ }^{16}$

To express this vision, let us think of factors positioned in a production space in accordance with their complementarities: the shorter the distance between two factors in this space, the greater the complementarity between them. Our analysis will indicate that firms position themselves in this production space so as to maximize the profit opportunities from the factor complementarities. In this way, factor complementarities are shown to influence both the boundaries of each firm and the number of firms.

How such a general equilibrium system is modeled depends on the types of factor complementarity under consideration. For brevity, we will consider only the first type of complementarity above, namely, that which gives rise to returns to scale. In particular, suppose that homogeneous bundles of

\footnotetext{
${ }^{16}$ The partial equilibrium analysis above of course does not deal with the equilibrium number of firms at all.
} 
factors are distributed uniformly around a unit circle, where the circumference of the circle (unity) represents the aggregate factor supply. Different firms occupy different segments of the factor circle.

Figure 1, for example, illustrates an economy containing three firms. The segment occupied by a single firm (indexed by $f=1,2,3$ ), consists of two parts, a factor bundle $x(f)$ that is used in production (the production segment) and a factor bundle $z(f)$ that covers the firm's internal transactions (the transactions segment). The sum of the two factor bundles comprises the total factor use of the firm and thereby provides a measure of the size of the firm.

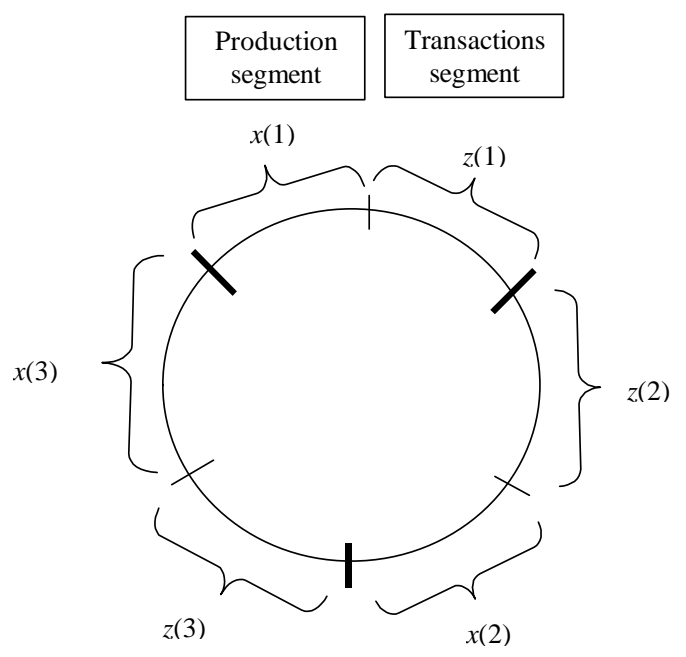

Fig. 1: Equilibrium Boundaries of

Firms

As in the previous section, the firm faces a tradeoff between returns to scale and internal transactions costs. The returns to scale of firm $f$ are given by the production function

$$
q(f)=A x(f)^{1+\alpha}
$$

where the output $q(f)$ is assumed to be a nondurable consumption good, and $A$ and $\alpha$ are positive constants. For simplicity, let us now interpret $x(f)$ as firm $f$ 's employment level (rather than as a factor bundle, as above). The firm's internal transactions costs (measured as real factor costs) are given by

$$
z(f)=B x(f)^{1+\beta}
$$

where $B$ and $\beta$ are positive constants. Note that all firms are assumed to face symmetric production and transactions technologies, and thus symmetric revenues and costs. The total length of the segment that firm $f$ occupies on the unit circle is $x(f)+z(f)$. The number of firms in the economy is $M^{F}$, so 
that $f=1, \ldots, M^{F}$.

Suppose that the economy contains a fixed number $M^{H}$ of identical households. For simplicity, let household $h\left(h=1, \ldots, M^{H}\right)$ have the following utility function:

$$
U(h)=q(h)^{\sigma}-e[x(h)+z(h)]
$$

where $q(h)$ is the household's consumption, $\sigma$ (a positive constant) is the elasticity of utility with respect to consumption, $x(h)$ is the hours of work supplied by household $h$, and $e$ is a positive constant.

Let $X$ be the aggregate amount of factors devoted to production and $Z$ be the aggregate amount of factors devoted to internal transactions. In equilibrium, the aggregate factor supplies (by the households) is equal to the aggregate factor demands (by the firms), in both production and internal transactions activities:

$$
\begin{aligned}
X & =\sum_{h=1}^{M^{H}} x(h)=\sum_{f=1}^{M^{F}} x(f) \\
Z & =\sum_{h=1}^{M^{H}} z(h)=\sum_{f=1}^{M^{F}} z(f)
\end{aligned}
$$

By symmetry,

$$
\begin{aligned}
& M^{H} x(h)=M^{F} x(f) \\
& M^{H} z(h)=M^{F} z(f)
\end{aligned}
$$

In the general equilibrium, firms position themselves around the factor circle so as to exploit the available gains from trade. For simplicity, we assume that externalities, imperfect competition and distributional issues are absent. (In particular, imperfect competition is absent in our analysis despite economies of scale in production, because at the margin these economies are dominated by diseconomies in transactions activities.) Consequently the general equilibrium coincides with the social optimum. This implies that each firm expands until the marginal utility from producing more output is exactly equal to the marginal disutility from using factors to cover the costs of its internal transactions.

The general equilibrium number of firms $\left(M^{F *}\right)$ and the general equilibrium size of each firm (measured by $x^{*}(f)+z^{*}(f)$ ) is such that there are no further profit opportunities to be exploited. 
Profit opportunities arise when it is possible to change the number of firms (and thus, for given factor supplies, change the size of each firm) so as to make the households better off. To find the equilibrium values $M^{F *}, X^{*}$, and $Z^{*}$, we maximize the social welfare function:

$$
\sum_{h=1}^{M^{H}}\left(q(h)^{\sigma}-e[x(h)+z(h)]\right)
$$

subject to the production function (13), the transactions function (14), and the factor constraints (16) - (19).

The social welfare function (20) may be rewritten as $\left(\frac{Q}{M^{H}}\right)^{\sigma}-e$, where $Q$ is aggregate output. ${ }^{17}$ The firm f's production function (13) may be expressed as an aggregate production function: $Q=$ $M^{F} A\left(\frac{1}{F} X\right)^{1+\alpha}$. Similarly, using (18) and (19), firm $f^{\prime}$ 's transaction function (14) may be expressed as an aggregate transactions function: $(1-X)=M^{F} B\left(\frac{X}{M^{F}}\right)^{1+\beta}$.

Thus, the market equilibrium may be derived as the solution to the following problem:

$$
\underset{X, M^{F}}{\operatorname{aximize}}\left(M^{F} A\left(\frac{1}{M^{F}} X\right)^{1+\alpha}\right)^{\sigma}
$$

subject to

$$
(1-X)=M^{F} B\left(\frac{X}{M^{F}}\right)^{1+\beta}
$$

The solution is

$$
\begin{aligned}
M^{F *} & =\frac{1}{\theta\left(1+B \theta^{\beta}\right)} \\
X^{*} & =\frac{1}{1+B \theta^{\beta}}
\end{aligned}
$$

where

$$
\theta=\left(\frac{\alpha}{\beta(\beta(1+\alpha)-\alpha(1+\beta))}\right)^{\frac{1}{\beta}}
$$

From these equations it is clear that

$$
\frac{\partial M^{F *}}{\partial \alpha}, \frac{\partial X^{*}}{\partial \alpha}<0, \text { and } \frac{\partial Z^{*}}{\partial \alpha}>0
$$

\footnotetext{
${ }^{17}$ Recall that $\sum_{h=1}^{H}(x(h)+z(h))=1$.
} 
Furthermore, in equilibrium, $x(f)=\frac{X^{*}}{M^{F *}}=\theta$, and since $\frac{\partial \theta}{\partial \alpha}>0$, we infer that

$$
\frac{\partial x^{*}(f)}{\partial \alpha}, \frac{\partial z^{*}(f)}{\partial \alpha}>0
$$

In words, the greater are the economies of scale in production (the greater is $\alpha$ ):

- the smaller will be the equilibrium number of firms $\left(F^{*}\right)$,

- the greater will be the size of each firm $\left(x^{*}(f)+z^{*}(f)\right)$,

- the smaller will be the aggregate amount of factors devoted to production $\left(X^{*}\right),{ }^{18}$ and

- the larger will be the aggregate amount of factors devoted to internal transactions $\left(Z^{*}\right)$.

\section{Conclusion}

This paper has provided an account of the firm as a pool of factor complementarities. Through a sequence of models we have shown how factor complementarities, together with the standard transactions costs, can determine the boundaries of the firm. Identifying factor complementarities as a unifying concept, our analysis is an attempt to integrate recent theories of the firm (that emphasize communication and coordination costs, principal-agent problems, and hold-up) with the literature on economies of scale and scope for individual production plants.

\footnotetext{
${ }^{18}$ Intuitively, the firm takes advantage of greater scale economies by economizing on its use of factors in production, while utilizing more factors for internal transactions.
} 


\section{References}

[1] Alchian, Alchian, and Harold Demsetz (1972), "Production, Information Costs, and Economic Organization," American Economic Review, Dec, 62(5), 777-95.

[2] Baumol, W., J. Panzer and R. Willig (1982), Contestable Markets and the Theory of Industry Structure, New York: Harcourt Brace Jovanovich.

[3] Bolton, Patrick, and Mathias Dewatripont (1994), "The Firm as a Communication Network," Quarterly Journal of Economics, 109(4), 809-839.

[4] Coase, Ronald (1937), "The Nature of the Firm," Economica, Nov., 4(4), 386-405.

[5] Grossman, Sanford and Oliver Hart (1986), "The Costs and Benefits of Ownership: A Theory of Vertical and Lateral Integration," Journal of Political Economy, August, 94(4), 691-719.

[6] Grout, Paul (1984), "Investment and Wages in the Absence of Binding Contracts: A Nash Bargaining Approach," Econometrica, 52, 449-60.

[7] Holmstrom, Bengt (1982), "Moral Hazard in Teams," Bell Journal of Economics, Autumn, 13(2), $324-40$.

[8] Klein, Benjamin, Robert Crawford and Armen Alchian (1978), "Vertical Integration, Appropriable Rents, and the Competitive Contracting Process," Journal of Law and Economics, 21, 297-326.

[9] Lindbeck, Assar, and Dennis J. Snower (1996), "Reorganization of Firms and Labor Market Inequality", |American Economic Review, 86(2), 315-321.

[10] Lindbeck, Assar, and Dennis J. Snower, (2000), "Multi-task Learning and the Reorganization of Work", Journal of Labor Economics, 18 (3), 353-376.

[11] Robinson, E. (1958), The Sturcture of Competitive Industry, revised edition, University of Chicago Press.

[12] Tirole, Jean (1989), The Theory of Industrial Organization, MIT Press.

[13] Viner, Jacob (1932), "Cost Curves and Supply Curves," Zeitschrift fur Nationalokonomie, 3, $23-46$. 
[14] Williamson, Oliver (1975), Markets and Hierarchies: Analysis and Antitrust Implications, New York: Free Press. 